\title{
The determining factors of peak nasal inspiratory flow and perception of nasal airflow in asthmatics*
}

\author{
Wenche Moe Thorstensen ${ }^{1,7}$, Malcolm Sue-Chu ${ }^{2,8}$, Vegard Bugten ${ }^{1,7}$, \\ Milada Cvancarova ${ }^{3}$, Sverre Karmhus Steinsvåg ${ }^{4,5,6}$ \\ ' Dept of Otolaryngology, Head and Neck Surgery, University Hospital of Trondheim, Trondheim, Norway \\ 2 Thoracic Medicine, St Olavs Hospital, University Hospital of Trondheim, Trondheim, Norway \\ ${ }^{3}$ Dept of Biostatistics, University of Oslo, Oslo, Norway \\ ${ }^{4}$ Dept of Otolaryngology, Head and Neck Surgery, Sorlandet Hospital, Kristiansand, Norway \\ ${ }^{5}$ Haukeland University Hospital, Bergen, Norway \\ ${ }^{6}$ University of Bergen, Bergen, Norway \\ ${ }^{7}$ Institute of Neuroscience, Norwegian University of Science and Technology, Trondheim, Norway \\ ${ }^{8}$ Circulation and Imaging, Norwegian University of Science and Technology, Trondheim, Norway
}

Rhinology 52: 348-354, 2014

DOl:10.4193/Rhino13.222

*Received for publication:

December 22, 2013

Accepted: March 2, 2014

\begin{abstract}
Background: The effect of pulmonary pathology on peak nasal inspiratory flow (PNIF) remains largely unknown. We investigated an association between a diagnosis of asthma and of lung function on PNIF when adjusted for possible confounders. Further, we investigated the perception of nasal obstruction in asthmatics compared to healthy controls when adjusted for PNIF.
\end{abstract}

Methodology: Eighty-seven asthmatics and 92 non-asthmatic controls underwent PNIF (categorized into groups of high, medium and low), acoustic rhinometry (AR) and spirometry, and we assessed symptoms of nasal obstruction on visual analogue scales (VAS) in three categories.

Results: PNIF was significantly associated with asthma and forced expiratory volume in the first second (FEV1) (\% predicted). Other factors associated with PNIF were the degree of nasal obstruction measured both subjectively on a VAS and objectively with AR, age and disease status. Asthma patients were 19 times more likely to be in a higher VAS category compared to non-asthmatic controls independent of PNIF group.

Conclusion: Special care has to be taken when interpreting PNIF values in patients with asthma or reduced FEV1 (\% predicted). The sensation of nasal obstruction in asthmatics is different from controls despite being in the same PNIF group.

Key words: asthma, rhinitis, Peak Nasal Inspiratory Flow, acoustic rhinometry, spirometry

\section{Introduction}

A large body of evidence supports the concept of a unified airway in which signs of disease in one part of the respiratory tract should be considered as a disease of the whole. This concept is sometimes expressed as "one airway, one disease" (1-3). Clinical studies show that bronchial provocation with grass pollen extract can induce nasal inflammation ${ }^{(4)}$ and nasal allergen challenge in patients with allergic rhinitis can lead to increased airway responsiveness ${ }^{(5)}$.
The incidence of asthma is increasing, and the concomitant presence of rhinitis and chronic rhinosinusitis with asthma is frequently seen ${ }^{(6)}$. Assessment of the degree of sino-nasal dysfunction in asthmatic patients has significant clinical impact since it is important to diagnose and treat pathology in the upper airways to relieve symptoms from the lower airways ${ }^{(7,8)}$. It is also known that rhinitis can be the first sign of a lower respiratory tract disorder and the degree of upper airway disease can to some extent determine the severity of lower airway disease ${ }^{(9)}$. 
A patient's sensation of nasal patency may be a challenge for the clinician because it can be difficult to relate the subjective feeling to anatomical and physiological variables, such as the internal nasal valve with minimal cross sectional area ${ }^{(10)}$ and airflow. Further, nasal patency assessment with objective measures, such as Peak Nasal Inspiratory Flow (PNIF), has been evaluated in a large number of studies on healthy individuals ${ }^{(11-13)}$, patients complaining of nasal obstruction ${ }^{(14)}$, medical treatment of the nose ${ }^{(15)}$, nasal surgery procedures ${ }^{(16,17)}$ and repeatability ${ }^{(18)}$. However, despite the well-known association between diseases in the upper and lower airways, very few have studied the use of PNIF on patients with pulmonary disorders ${ }^{(19,20)}$.

The aim of the present study was to investigate the effect of a diagnosis of asthma and of lung function on PNIF when adjusted for possible confounders. Further, we investigated the perception of nasal obstruction in asthmatics compared to healthy controls when adjusted for PNIF.

\section{Materials and methods}

\section{Study population}

A cross-sectional study was conducted on 179 adult subjects consisting of 87 physician-diagnosed asthma patients and 92 non asthmatic controls. The sample, nasal recordings, questionnaires, and additional recordings were extracted from a database described previously ${ }^{(21)}$.

Asthma was defined as the presence of typical asthma symptoms, variable airflow obstruction and in accordance with the British Thoracic Society criteria ${ }^{(22)}$. Variable airflow obstruction was defined by at least one of the two following criteria: an increase of $\geq 12 \%$ and $\geq 200 \mathrm{ml}$ in the forced expiratory volume in the first second (FEV1) from baseline and after administration of salbutamol, or a positive bronchial provocation test, defined as the provocative dose of methacholine of $\leq 1600 \mu \mathrm{g}$ that causes a fall in FEV1 of at least 20\% from baseline. Exclusion criteria were pregnancy, a history of cancer, previous nasal surgery, systemic disease with potential affection of the nose such as granulomatosis with polyangiitis (Wegener's granulomatosis), cystic fibrosis, primary ciliary dyskinesia, Kartagener's syndrome and sarcoidosis, and the presence of acute and chronic rhinosinusitis and nasal polyposis on oto-rhino-laryngological examination as defined by the EPOS2012 criteria ${ }^{(23)}$. Control subjects with allergy were not investigated in the pollen season (May-August) and asthmatic subjects were investigated from September 2009 to February 2010.

Written informed consent was obtained from all subjects. The study was approved by the Regional Committees for Medical and Health Research Ethics of Norway and investigations were performed in accordance with the principles of the Declaration of Helsinki.

\section{Peak Nasal Inspiratory Flow (PNIF)}

Nasal patency was assessed with a portable PNIF meter (Incheck DIAL, Clement Clarke International, Harlow, Essex, UK). A forced maximum inhalation through the nose from residual volume was performed with the subject sitting in an upright position. Three satisfactory maximal nasal inspirations were obtained, and the mean value was calculated.

The scale on the PNIF meter was from 15 to 120 liters/minute (L/ $\mathrm{min}$ ). A flow in excess of $120 \mathrm{~L} / \mathrm{min}$ was recorded as $120+\mathrm{L} / \mathrm{min}$, and for the purpose of statistical analysis set to $120 \mathrm{~L} / \mathrm{min}$.

\section{Spirometry}

Lung function was assessed by flow-volume spirometry measurements (Spirostar USB spirometer, Medikro Oy, Kuopio, Finland) at room temperature. The best FEV1 in liters and percentage of predicted (\% predicted) ${ }^{(24)}$ of three acceptable attempts was recorded, in accordance with international guidelines ${ }^{(25)}$. Predicted normal values were based on reference values of Crapo et al. ${ }^{(24)}$.

\section{Nasal minimal cross sectional area}

The cross sectional areas from the nasal orifice to a depth of 5.2 $\mathrm{cm}$ into the nasal cavity were assessed with acoustic rhinometry (RhinoMetrics SRE2100, Rhinoscan version 2.5, built 3.2.5.0; Interacoustics, Minneapolis, MN, USA) by two trained operators throughout the study. Recordings were performed according to published protocols ${ }^{(26)}$. Three recordings were made from each nasal cavity. The mean value for each side was calculated from contiguous cross sectional areas from 0 to $3 \mathrm{~cm}$ and from 3 to 5.2 $\mathrm{cm}$. To account for variations between nostrils due to the nasal cycle, the average of the two mean values for each partition was calculated. The lower of the two averages was defined as the

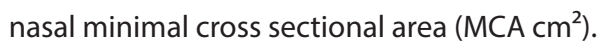

\section{Allergy}

Sensitization to pollen (birch, grass and mugwort), cladosporium, house dust mite (Dermatophagoides pteronyssinus), and animal epithelia (horse, dog, and cat) was determined by skin prick testing (Soluprick SQ, ALK-Abello, Horsholm, Denmark) or measurement of specific lgE (AlaTOP, Diagnostics Products Corp., Los Angeles, CA, USA). Antihistamines were discontinued 4 days prior to the skin prick test. Allergy was defined as a positive test (reaction with $\mathrm{a} \geq 3$-mm-diameter wheal or specific IgE concentration of $0.7 \mathrm{IU} / \mathrm{ml}$ or greater) and typical symptoms of hypersensitivity on exposure to the allergen(s).

\section{Nasal obstruction}

The subjective degree of nasal obstruction during the previous week was assessed on a $100 \mathrm{~mm}$ Visual Analog Scale (NO-VAS) and the endpoints were $0 \mathrm{~mm}$ (never) and $100 \mathrm{~mm}$ (always). 
Table 1. Demographic data on asthmatics and controls.

\begin{tabular}{|c|c|c|c|c|}
\hline Variable & Total, $n=179$ & Asthma, $n=87$ & Control, $\mathrm{n}=92$ & $\mathbf{p}$ \\
\hline Age, years median, (range) & $44(19-65)$ & $44(19-64)$ & $44(20-65)$ & 0.91 \\
\hline $\mathrm{BMI}, \mathrm{kg} / \mathrm{m}^{2}$ median, (range) & $25.4(18.0-44.3)$ & $25.7(18.5-44.3)$ & $25.0(18.0-35.4)$ & 0.08 \\
\hline Sex, Male/female & $76 / 103$ & $36 / 51$ & $40 / 52$ & 0.78 \\
\hline Allergy n (\%) & $72(40)$ & $52(60)$ & $20(22)$ & $<0.01$ \\
\hline Smoking status: Ever/Never & $32 / 147$ & $11 / 76$ & $21 / 71$ & 0.08 \\
\hline Level of education in year & & & & $<0.01$ \\
\hline$\leq 9$ years $n(\%)$ & $36(20)$ & $15(42)$ & $21(58)$ & \\
\hline 10 to 12 years $n(\%)$ & $75(42)$ & $47(63)$ & $28(37)$ & \\
\hline$\geq 13$ years $n(\%)$ & $68(38)$ & $25(37)$ & $43(63)$ & \\
\hline
\end{tabular}

$\mathrm{BMI}=$ body mass index

\section{Statistical analysis}

Data were described with median and range for continuous variables and with count and percentages for categorical variables. Crude associations between pairs of categorical variables were assessed with Chi-square tests.

The level of education was categorized as either basic $(\leq 9$ years), secondary (10 to 12 years), or tertiary ( $\geq 13$ years), that has been shown to be a good surrogate for socioeconomic status in Norway ${ }^{(27,28)}$. Subject co-morbidity was defined as the regular use of medication during the last 6 months prior to recruitment for asthma and allergy, pain relief, ischemic heart disease and hypertension, musculoskeletal disease, thyroid disorders, diabetes mellitus, anxiety and depression. Disease status was categorized as cardiovascular disease, other disease and no disease. Smoking status was dichotomized as smoker (current or ever smoked) and nonsmoker, as we did not have precise information about cigarette consumption.

NO-VAS was categorized as mild (0-30 mm), moderate (31-70 $\mathrm{mm}$ ) and severe (71-100 mm) ${ }^{(29)}$. PNIF was used as a continuous variable for linear regression analysis and as an ordinal variable for ordinal logistic regression analysis. For the latter analysis, PNIF was categorized into the following 3 groups: (1) high: $\geq 120$ L/min, (2) medium: 90 - $119 \mathrm{~L} / \mathrm{min}$ and (3) low: $15-89 \mathrm{~L} / \mathrm{min}$. Of the spirometry variables, FEV1 is the most robust, and FEV1 (\% predicted) was chosen for linear regression as that is based on height, age, sex and ethnicity of the subject. As there was a strong association between asthma and FEV1 (\% predicted) (t-test, $\mathrm{p}<0.001$ ), we fitted two separate models for PNIF as a continuous variable to avoid multicollinearity. The associations between PNIF and asthma and between PNIF and FEV1 (\% pre- dicted) were modeled with linear regression. Possible confounders such as allergy, other diseases, education, NO-VAS, MCA, weight, height, age, sex and smoking were tested. The model fit was good and assumption of normally distributed residuals was fulfilled.

Further, we fitted ordinal logistic regression to assess possible association between VAS (in three categories) and having asthma. PNIF was omitted from the final model as we found the same ratio between having asthma and VAS score when stratified by PNIF group so there was no interaction between PNIF and asthma. The assumption of parallel lines was fulfilled and the model fit was good. The results were expressed as odds ratios (OR) with $95 \%$ confidence intervals (CI).

All statistical analyses were performed using PASW Statistics, version 20 for Windows (SPSS Inc., Chicago, IL, USA). A p-value of $<0.01$ was considered statistically significant to correct for multiple testing.

\section{Results}

Subject characteristics are presented in Table 1. Allergy was present in $60 \%(n=52)$ of asthmatics and $22 \%(n=20)$ of controls. The association between asthma and PNIF is shown in Model 1 (Table 2A). PNIF was significantly associated with asthma, MCA and age $(p<0.01)$. When all other confounders were kept equal, PNIF was $10 \mathrm{~L} / \mathrm{min}$ lower in asthmatics than non-asthmatics. Further, PNIF was increased by $4.9 \mathrm{~L} / \mathrm{min}$ for a $0.1 \mathrm{~cm}^{2}$ increase in $\mathrm{MCA}$, and was decreased by $0.4 \mathrm{~L} / \mathrm{min}$ per one year increase in age.

The association between FEV1 (\% predicted) and PNIF is shown in Model 2 (Table 2B). PNIF was significantly associated with 
Table 2. Multiple linear regression for PNIF as a dependent variable.

A) Model 1: Asthma as an independent variable adjusted for confounders. $\mathrm{N}=179$

\begin{tabular}{|c|c|c|c|}
\hline Variable & Estimate of $\beta$ & $95 \% \mathrm{Cl}$ & p-value \\
\hline Asthma [no=ref] & -10.2 & -17.8 to -2.7 & $<0.01$ \\
\hline Allergy $[\mathrm{no}=\mathrm{ref}]$ & -0.1 & -6.6 to 6.4 & 0.98 \\
\hline Disease status [no=ref] & -4.7 & -8.6 to -0.7 & 0.02 \\
\hline Education level [basic=ref] & 2.5 & -2.1 to 7.0 & 0.29 \\
\hline NO-VAS [mm] & -0.2 & -0.3 to -0.01 & 0.03 \\
\hline $\mathrm{MCA}\left[0.1 \mathrm{~cm}^{2}\right]$ & 4.9 & 2.2 to 7.6 & $<0.01$ \\
\hline Weight [kg] & 0.2 & 0.0 to 0.5 & 0.05 \\
\hline Height $[\mathrm{cm}]$ & -0.1 & -0.6 to 0.4 & 0.8 \\
\hline Age [years] & -0.4 & -0.6 to -0.1 & $<0.01$ \\
\hline Sex $[$ male $=$ ref $]$ & -3.1 & -12.6 to 6.4 & 0.5 \\
\hline Smoking [ever=ref] & 0.5 & -7.2 to 8.3 & 0.9 \\
\hline
\end{tabular}

B) Model 2: FEV1 (\% predicted) as an independent variable adjusted for confounders. $\mathrm{N}=179$

\begin{tabular}{|c|c|c|c|}
\hline Variable & Estimate of $\beta$ & $95 \% \mathrm{Cl}$ & p-value \\
\hline FEV1 (\% predicted) [\%] & 0.3 & 0.1 to 0.5 & $<0.01$ \\
\hline Allergy [no=ref] & -0.3 & -6.4 to 5.9 & 0.9 \\
\hline Disease status [no=ref] & -6.1 & -9.9 to -2.4 & $<0.01$ \\
\hline Education [basic=ref] & 4.5 & 0.4 to 8.6 & 0.03 \\
\hline NO-VAS [mm] & -0.2 & -0.3 to -0.07 & $<0.01$ \\
\hline MCA [0.1 cm2] & 5.1 & 2.5 to 7.6 & $<0.01$ \\
\hline Weight [kg] & 0.2 & 0.1 to 0.4 & 0.01 \\
\hline Smoking [ever=ref] & 2.7 & -4.9 to 10.5 & 0.5 \\
\hline
\end{tabular}

Estimate of beta $=$ the amount of change in the response variable when the explanatory variable is increased by one unit. FEV1 $=$ forced expiratory volume in the first second, MCA = minimal cross sectional area, NO-VAS = nasal obstruction visual analogue scale, PNIF = peak nasal inspiratory flow ref $=$ reference category for categorical variables.

FEV1 (\% predicted), MCA, NO-VAS and other disease $(p<0.01)$. When all other confounders were kept equal, PNIF increased by $0.3 \mathrm{~L} / \mathrm{min}$ per \% increase in FEV1 (\% predicted), and increased by $5.1 \mathrm{~L} / \mathrm{min}$ for every $0.1 \mathrm{~cm}^{2}$ increase in MCA. There was a decrease of $0.2 \mathrm{~L} / \mathrm{min}$ in PNIF per mm increase in NO-VAS and a decrease of $6.1 \mathrm{~L} / \mathrm{min}$ in PNIF in subjects categorized with a disease.
Allergy and smoking status were not significantly associated with PNIF in any of the adjusted analyses.

Asthma patients were 19 times more likely to be in a higher VAS category compared to non-asthmatic controls (OR $=19.4,95 \%$ $\mathrm{Cl} 7.2-52.5, \mathrm{p}<0.001)$. The odds ratio was independent of the PNIF group (Figure 1). 


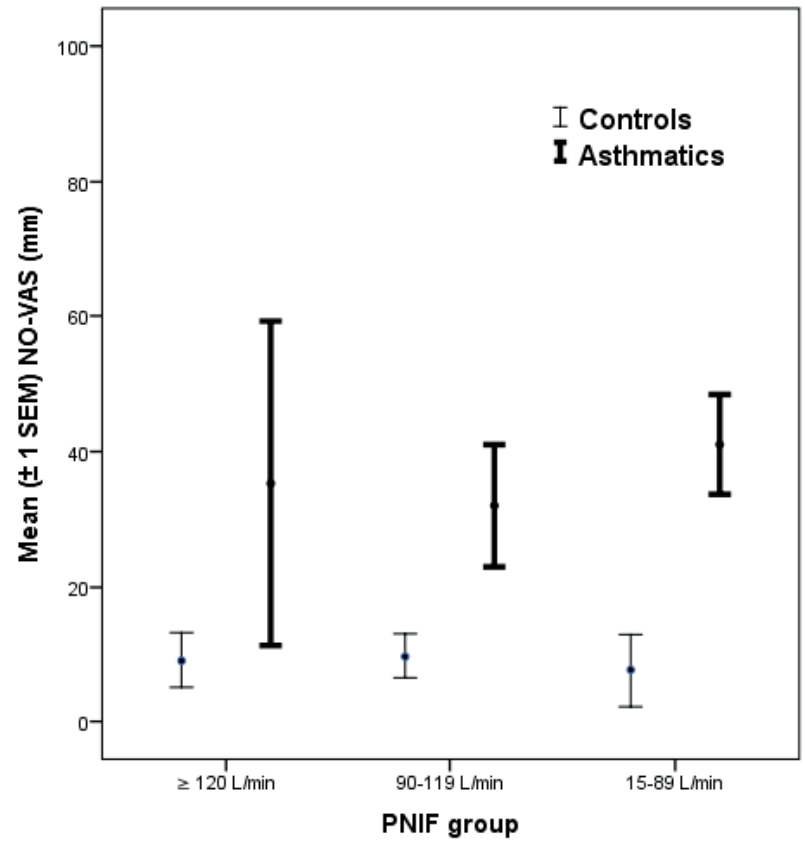

Figure 1. NO-VAS distribution according to PNIF group in asthmatics and controls. $\mathrm{NO}-\mathrm{VAS}=$ nasal obstruction visual analogue scale, $\mathrm{PNIF}=$ peak nasal inspiratory flow.

\section{Discussion}

This study demonstrates that PNIF is influenced by an asthma diagnosis and FEV1 (\% predicted), and that asthmatics are more likely to be in a higher NO-VAS category which is independent of PNIF group. Other factors associated with PNIF are the degree of nasal obstruction measured both subjectively on a visual analogue scale and objectively with acoustic rhinometry, age and disease status. Thus in patients presenting with nasal obstruction PNIF recordings should be assessed in conjunction with an asthma diagnosis, spirometry and MCA.

In the present study, PNIF is $10 \mathrm{~L} / \mathrm{min}$ lower in asthmatics than in non-asthmatics and increases by $0.3 \mathrm{~L} / \mathrm{min}$ for every $\%$ increase in FEV1 (\% predicted). Thus, when confronted with a patient with nasal obstruction without an obvious rhinological cause, the possibility of asthma should be considered. The clinician should enquire about lower respiratory tract symptoms suggestive of asthma and seek evidence of variable airflow obstruction either with spirometry and reversibility testing or assessing the degree of bronchial hyperresponsiveness. Previous studies show a positive correlation between upper airway patency measured by PNIF and lower airway function measured by PEF in adults ${ }^{(12)}$ and in children and adolescents ${ }^{(30)}$. Moreover, an increase in PNIF with a concomitant increase in FEV1 (\% predicted) has been reported in allergic rhinitis after sauna treatment ${ }^{(31)}$. PNIF increased by 4.9-5.1 L/min per $0.1 \mathrm{~cm}^{2}$ increase in MCA when modeled with respect to an asthma diagnosis (Model 1) or by FEV1 (\% predicted) as in model 2. The MCA in our sample was located between 0-3 cm from the nasal orifice in almost all of our subjects (95\% of asthmatics and $98 \%$ of controls) ${ }^{(21)}$. The internal nasal valve is generally accepted to be located at a distance of $2-3 \mathrm{~cm}$ from the nasal orifice ${ }^{(10,32)}$, and surgical procedures performed at the internal nasal valve improve MCA ${ }^{(33-35)}$. Improvement in MCA should lead to a significant improvement in nasal airflow as Poiseuille's law states that flow is directly proportional to the difference in pressure times the radius raised to the fourth power ${ }^{(36)}$, even though modifications due to the complex flow patterns in the human nose must be taken into consideration ${ }^{(37)}$. Thus, in asthmatics with obstructed noses, surgical intervention with procedures aimed at the internal nasal valve, could lead to an improvement in nasal air flow which in turn might be beneficial for the lower airways.

We have also shown that asthmatics have a different sensation of nasal obstruction compared to non-asthmatics despite being in the same PNIF group. The likelihood of being in a higher NOVAS category is 19-fold greater in asthmatics than in non-asthmatic subjects. However, the inter-individual variation is large, as confirmed by the wide confidence interval and it is thus difficult to quantify this association with better precision. Despite this, one can speculate whether an increased number of sensory sodium channels and sensory- and secretomotor nerve fibers in the nasal mucosa, that has been reported in allergic and nonallergic rhinitis ${ }^{(38,39)}$, may account for the increased perception of nasal obstruction. The level of perceived breathing difficulty has been reported to be more important than the applied nasal load for the increased propensity of asthmatics to switch to oronasal breathing, compared with non-asthmatic subjects ${ }^{(40)}$. Premature switching to oronasal breathing results in inadequate conditioning and filtering of the inspired air, with drying and cooling of the lower airways, subsequent release of inflammatory cell mediators and development of an asthmatic response (41) and asthma chronicity.

The main strengths of our study are the large sample size, possibility to compare asthmatics with non-asthmatics, and the complete information of many possible confounders. However, the study has some limitations. Smoking is known to be under-reported, and we only have information about ever- and never smokers. The information about other diseases was selfreported and might be underestimated. The non-asthmatics were individuals recruited from businesses near by the hospital or patients attending the hospital for other illnesses, which were thought not to affect the upper and lower airways. Those who chose to participate may have been more interested in their health than the general population, but still we regard measurements on these individuals to be representative for the general population. 
There are different PNIF meters in clinical use, and our study is based on In-check DIAL which has a scale from 15 to $120 \mathrm{~L} /$ min. A normal value of greater than $120 \mathrm{~L} / \mathrm{min}$ is commonly

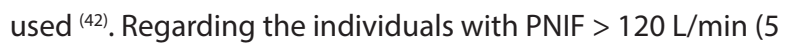
asthmatics and 21 controls), we have performed sensitivity analysis where these individuals were omitted which confirms our original findings.

Mainly turbulent airflow prevails at tidal volumes reached during maximum inspiration ${ }^{(43)}$ and thus PNIF does not reflect the nasal resistance during resting respiration. Possible reasons for inaccuracy of the PNIF include random error and operation errors such as measurement with loose face masks or incompletely closed mouth, but these errors were minimalized by two trained operators throughout the study. The present study emphasizes that special care has to be taken when interpreting PNIF values in patients with asthma or reduced FEV1 (\% predicted). The sensation of nasal obstruc- tion in asthmatics is different from controls despite being in the same PNIF group.

\begin{abstract}
Authorship contribution
WMT: Study design, data collection, statistical analysis, paper drafting; MSC: Data collection, paper drafting; VB: Data collection, paper drafting; MC: Statistical analysis; SKS: Study design, paper drafting.
\end{abstract}

\section{Conflicts of Interest}

None declared.

\section{Acknowledgement}

We thank the research nurses Else Bartnes and Petra Aspås, Mr.Leif Richard Erichsen and Mrs. Maren Hertzberg Erichsen Benevolent Fund, and the Liaison Committee between the Central Norway Regional Health Authority (RHA) and the Norwegian University of Science and Technology (NTNU).

\section{References}

1. Bachert C, Vignola AM, Gevaert P, Leynaert B, Van Cauwenberge P, Bousquet J. Allergic rhinitis, rhinosinusitis, and asthma: one airway disease. Immunol Allergy Clin North Am. 2004; 24: 19-43.

2. Jani AL, Hamilos DL. Current thinking on the relationship between rhinosinusitis and asthma. J Asthma. 2005; 42: 1-7.

3. Jarvis D, Newson R, Lotvall J, et al. Asthma in adults and its association with chronic rhinosinusitis: the GA2LEN survey in Europe. Allergy. 67: 91-98.

4. Braunstahl GJ, Kleinjan A, Overbeek SE, Prins JB, Hoogsteden HC, Fokkens WJ. Segmenta bronchial provocation induces nasal inflammation in allergic rhinitis patients. Am J Respir Crit Care Med. 2000; 161: 2051-2057.

5. Bonay M, Neukirch C, Grandsaigne M, et al. Changes in airway inflammation following nasal allergic challenge in patients with seasonal rhinitis. Allergy. 2006; 61: 111-118.

6. Bousquet J, Khaltaev N, Cruz AA, et al. Allergic Rhinitis and its Impact on Asthma (ARIA) 2008 update (in collaboration with the World Health Organization, GA(2)LEN and AllerGen). Allergy. 2008; 63: 8-160.

7. Dahl R, Nielsen LP, Kips J, et al. Intranasal and inhaled fluticasone propionate for pollen-induced rhinitis and asthma. Allergy. 2005; 60: 875-881.

8. Crystal-Peters J, Neslusan C, Crown WH, Torres A. Treating allergic rhinitis in patients with comorbid asthma: the risk of asthmarelated hospitalizations and emergency department visits. J Allergy Clin Immunol. 2002; 109: 57-62

9. Van Cauwenberge P, Watelet JB, Van Zele $T$, et al. Spreading excellence in allergy and asthma: the GA2 LEN (Global Allergy and Asthma European Network) project. Allergy.
2005; 60: 858-864

10. Roithmann R, Chapnik J, Zamel N, Barreto SM, Cole P. Acoustic rhinometric assessment of the nasal valve. Am J Rhinol. 1997; 11: 379-385.

11. Ottaviano G, Scadding GK, Coles S, Lund VJ. Peak nasal inspiratory flow; normal range in adult population. Rhinology. 2006; 44 32-35.

12. Ottaviano G, Lund VJ, Coles S, Staffieri A, Scadding GK. Does peak nasal inspiratory flow relate to peak expiratory flow? Rhinology. 2008; 46: 200-203.

13. Ottaviano G, Scadding GK, Scarpa B, Accordi D, Staffieri A, Lund VJ. Unilateral peak nasa inspiratory flow, normal values in adult population. Rhinology. 2012; 50: 386-392.

14. Ottaviano G. Comparison between unilateral PNIF and rhinomanometry in healthy and obstructed noses. Rhinology. 2013; 51.

15. Koo Ng NK, Young D, McGarry GW. Reversible nasal airway obstruction: does change in nasal peak inspiratory flow following decongestion predict response to topical steroids in chronic rhinosinusitis patients? J Laryngol Otol. 2012; 126: 12381240.

16. Valstar MH, Baas EM, Te Rijdt JP, De Bondt BJ, Laurens E, De Lange J. Maxillary sinus recovery and nasal ventilation after Le Fort I osteotomy: a prospective clinical, endoscopic, functional and radiographic evaluation. Int J Oral Maxillofac Surg. 2013; 42: 1431-1436.

17. Ozkul HM, Balikci HH, Gurdal MM, et al. Normal range of peak nasal inspiratory flow and its role in nasal septal surgery. J Craniofac Surg. 2013; 24: 900-902.

18. Starling-Schwanz R, Peake HL, Salome CM, et al. Repeatability of peak nasal inspiratory flow measurements and utility for assessing the severity of rhinitis. Allergy. 2005; 60:
795-800.

19. Rimmer J, Greenwood A, Bartlett D, Hellgren J. Nasal steroids improve regulation of nasal patency in asthma and mild rhinitis: a randomised, cross-over trial. Eur Arch Otorhinolaryngol. 2012; 269: 11331138

20. Mastalerz L, Milewski M, Duplaga M Nizankowska E, Szczeklik A. Intranasal fluticasone propionate for chronic eosinophilic rhinitis in patients with aspirin-induced asthma. Allergy. 1997; 52: 895-900.

21. Thorstensen WM, Sue-Chu M, Bugten V, Steinsvag SK. Nasal flow, volumes, and minimal cross sectional areas in asthmatics. Respir Med. 2013.

22. British Guideline on the Management of Asthma. Thorax. 2008; 63: iv1-121.

23. Fokkens WJ, Lund VJ, Mullol J, et al. EPOS 2012: European position paper on rhinosinusitis and nasal polyps 2012. A summary for otorhinolaryngologists. Rhinology. 50: 1-12.

24. Crapo RO, Morris AH, Gardner RM. Reference spirometric values using techniques and equipment that meet ATS recommendations. Am Rev Respir Dis. 1981; 123: 659-664.

25. Miller MR, Hankinson J, Brusasco V, et al. Standardisation of spirometry. Eur Respir J. 2005; 26: 319-338.

26. Hilberg O, Pedersen OF. Acoustic rhinometry: recommendations for technical specifications and standard operating procedures. Rhinol Suppl. 2000; 16: 3-17

27. Krokstad S, Kunst AE, Westin S. Trends in health inequalities by educational level in a Norwegian total population study. J Epidemiol Community Health. 2002; 56: 375-380.

28. Strand BH, Groholt EK, Steingrimsdottir 
OA, Blakely T, Graff-Iversen S, Naess O Educational inequalities in mortality over four decades in Norway: prospective study of middle aged men and women followed for cause specific mortality, 1960-2000. BMJ. 2010; 340: c654

29. Kjaergaard T, Cvancarova M, Steinsvag SK. Does nasal obstruction mean that the nose is obstructed? Laryngoscope. 2008; 118: 1476-1481.

30. Chaves C, Ibiapina Cda C, de Andrade CR, Godinho R, Alvim CG, Cruz AA. Correlation between peak nasal inspiratory flow and peak expiratory flow in children and adolescents. Rhinology. 2012; 50: 381-385.

31. Kunbootsri N, Janyacharoen $T$ Arrayawichanon $\mathrm{P}$, et al. The effect of sixweeks of sauna on treatment autonomic nervous system, peak nasal inspiratory flow and lung functions of allergic rhinitis Thai patients. Asian Pac J Allergy Immunol. 2013; 31: 142-147.

32. Shaida AM, Kenyon GS. The nasal valves: changes in anatomy and physiology in normal subjects. Rhinology. 2000; 38: 7-12.

33. Islam A, Arslan N, Felek SA, Celik H, Demirci $\mathrm{M}, \mathrm{Oguz} \mathrm{H}$. Reconstruction of the internal nasal valve: modified splay graft technique with endonasal approach. Laryngoscope. 2008; 118: 1739-1743.

34. Friedman M, Ibrahim H, Lee G, Joseph NJ. A simplified technique for airway correction at the nasal valve area. Otolaryngol Head Neck Surg. 2004; 131: 519-524.

35. Huang C, Manarey CR, Anand VK. Endoscopic placement of spreader grafts in the nasal valve. Otolaryngol Head Neck Surg. 2006; 134: 1001-1005.

36. Pfitzner J. Poiseuille and his law. Anaesthesia. 1976; 31: 273-275.

37. Doorly DJ, Taylor DJ, Gambaruto AM, Schroter RC, Tolley N. Nasal architecture: form and flow. Philos Transact A Math Phys Eng Sci. 2008; 366: 3225-3246.

38. Keh SM, Facer P, Simpson KD, Sandhu G, Saleh HA, Anand P. Increased nerve fiber expression of sensory sodium channels Nav1.7. Nav1.8, And Nav1.9 in rhinitis. Laryngoscope. 2008; 118: 573-579.

39. O'Hanlon S, Facer P, Simpson KD, Sandhu $G$, Saleh HA, Anand P. Neuronal markers in allergic rhinitis: expression and correlation with sensory testing. Laryngoscope. 2007; 117: 1519-1527.

40. Hallani M, Wheatley JR, Amis TC. Initiating oral breathing in response to nasal loading: asthmatics versus healthy subjects. Eur Respir J. 2008; 31: 800-806

41. Anderson SD, Rodwell LT, Daviskas E, Spring JF, du Toit J. The protective effect of nedocromil sodium and other drugs on airway narrowing provoked by hyperosmolar stimuli: a role for the airway epithelium? J Allergy Clin Immunol. 1996; 98: S124-134; discussion S140-122

42. Bermuller $C$, Kirsche $H$, Rettinger $G$, Riechelmann H. Diagnostic accuracy of peak nasal inspiratory flow and rhinomanometry in functional rhinosurgery. Laryngoscope. 2008; 118: 605-610.

43. Clement PA, Gordts F. Consensus report on acoustic rhinometry and rhinomanometry. Rhinology. 2005; 43: 169-179.

Dr Wenche Moe Thorstensen

Dept of Otolaryngology

Head and Neck Surgery

St Olavs Hospital

University Hospital of Trondheim, and Institute of Neuroscience, Norwegian University of Science and Technology, 7006 Trondheim

Norway

Tel: +47-72-57-4478

Fax: +47-72-57-5766

E-mail: wenche.m.thorstensen@ntnu. no

\section{ADVERTISEMENT}

\section{2th INTERNATIONAL COURSE IN ADVANCED SINUS SURGERY TECHNIQUES}

'How to get rid of the red'

Dissection course with fresh frozen cadaver heads

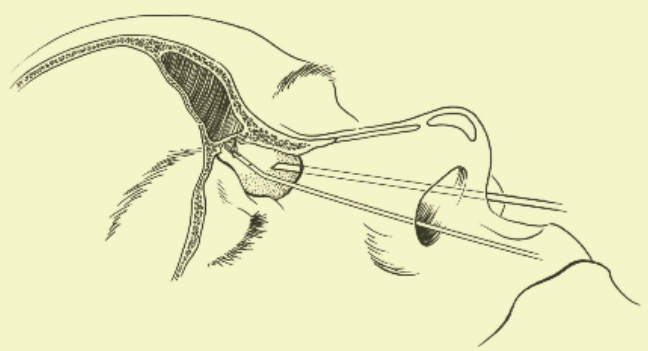

March 26-27, 2015

Department of Otorhinolaryngology Academic Medical Center of the University of Amsterdam The Netherlands

For further information contact Wytske J. Fokkens, $M D, P h D$ ENT dept. AMC Course Secretariat

Tel: 0031205668586 / Fax 0031205669573

Email:m.b.vanhuiden@amc.uva.nl

Web: www.sinuscourse.nl 